\title{
The Importance of Early Diagnosis in Iatrogenic Colon Perforation After Colonoscopy
}

\section{Kolonoskopi Sonrası İatrojenik Kolon Perforasyonunda Erken Tanının Önemi}

\author{
Bülent Aksel $^{1}$, Mahmut Onur Kültüroğlu \\ ${ }^{1}$ Sağlık Bilimleri Üniversitesi Ankara Onkoloji Eğitim ve Araştırma Hastanesi, Genel Cerrahi Kliniği, Ankara \\ ${ }^{2}$ Sağlık Bakanlığı Halil Şıvgın Çubuk Devlet Hastanesi, Genel Cerrahi, Ankara
}

\begin{abstract}
ÖZET
GíRIŞ ve AMAÇ: Kolonoskopi, kolorektal hastalıkların tarama, tanı ve tedavisinde en önemli yöntemdir. Çalışmamızda iatrojenik kolon perforasyonunda erken müdahalenin önemine dikkat çekmek amaçlanmıştır. YÖNTEM ve GEREÇLER: 2014-2018 yılları arasında hastanemizde yapılan 9,840 kolonoskopi işlemi retrospektif olarak taranmıştır.

BULGULAR: Yapılan 9,840 kolonoskopi sonrasında toplamda 5 hastada iatrojenik perforasyon olduğu görülmüştür. Dört hastada perforasyonun işlem esnasında farkedildiği ve hemen işlem sonrasında müdahale edilerek laparoskopik stapler ile onarım yapıldığı görülmüștür. Bir hastanın ise kolonoskopi sonrası birinci günde farkedildiği ve Hartman prosedürü uygulandığ görülmüştür.

TARTIŞMA ve SONUÇ: Kolonoskopi güvenli bir işlem olarak tanımlansa da nadiren komplikasyonlar görülmektedir. Kolonoskopi sonrasında görülen en morbid komplikasyon perforasyondur. Literatürde perforasyon oranı $\% 0,005$ ile $\% 0,63$ arasında gösterilmektedir. Çalışmamızda literatür ile uyumlu şekilde perforasyon oranı $\% 0,051$ olarak tespit edilmiştir. Perforasyonun erken dönemde tanınması ve müdahale edilmesi hasta morbiditesi açısından çok önemlidir. Erken dönemde tanı konması durumunda endoskopik onarım, laparoskopik primer onarım gibi morbiditesi daha düşük onarımlar yapılabilmektedir. Tanının gecikmesi durumunda ise batının kontamine olması nedeniyle Hartman prosedürü gibi daha morbid müdahalelerin yapılması gerekmektedir. İatrojenik perforasyon sonrasında tedavi yöntemi seçimi; hasta özellikleri, perforasyonun lokalizasyonu, boyutu ve perforasyon sonrası geçen süreye göre vaka bazlı yapılmalıdır.
\end{abstract}

Anahtar Kelimeler: Kolorektal kanser, Kolonoskopi, Perforasyon

ABSTRACT
INTRODUCTION: Colonoscopy is the most important method in the screening, diagnosis and treatment of colorectal diseases. In our study, it was aimed to emphasize the importance of early intervention in iatrogenic colon perforation.

METHODS: 9,840 colonoscopy procedures performed in our hospital between 2014-2018 were retrospectively reviewed.

RESULTS: After 9,840 colonoscopy, total iatrogenic perforation was observed in 5 patients. In four patients, perforation was noticed during the procedure and immediately after the procedure was performed and repair was performed with laparoscopic stapler. One patient was noticed on the first day after colonoscopy and Hartman procedure was performed.

DISCUSSION AND CONCLUSION: Although colonoscopy is defined as a safe procedure, complications are rarely seen. The most morbid complication after colonoscopy is perforation. The perforation rate in the literature is between $0.005 \%$ and $0.63 \%$. In our study, perforation rate was determined as $0,051 \%$ in accordance with the literature. Early recognition and intervention of perforation is very important for patient morbidity. In case of early diagnosis, endoscopic repair and laparoscopic primary repair can be performed with lower morbidity. In case of delayed diagnosis, more morbid interventions such as Hartman procedure should be performed because of the contaminated abdomen. Selection of treatment method after iatrogenic perforation; patient characteristics should be based on the location of the perforation, size and time after perforation.

Keywords: Colorectal cancer, Colonoscopy, Perforation 


\section{GíRIŞ}

Kolonoskopi, kolorektal hastalıkların tarama, $\tan 1$ ve tedavisinde en önemli tan1 yöntemlerinden biridir. Kolonoskopinin tarama yöntemi olarak kullanılmasından sonra kolorektal kanserden ölüm oranı ciddi miktarda azalmıştır (1). Kolonoskopi güvenli bir işlem olarak tanımlansa da nadiren komplikasyonlar görülmektedir. Kolonoskopi sonrasinda görülen en morbid komplikasyon perforasyondur. Kolonoskopinin yaygin olarak kullanılması ile birlikte kolonoskopi sonras1 görülen perforasyonlar ile ilgili çok sayıda yayın yapılmıştır. Bu çalışmalarda perforasyon oranı $\% 0,005$ ile $\% 0,63$ arasında geniş bir aralıkta verilmiştir (2-4). Perforasyon sonras1 bağırsak içeriğinin periton boşluğuna sızıntısı, sepsise kadar gidebilir ve önemli morbidite ve mortaliteye yol açabilir. $\mathrm{Bu}$ nedenle perforasyonlar hizlıca kapatılmalıdır (5).

$\mathrm{Bu}$ çalışmada iatrojenik kolon perforasyonlarında erken tanının hasta morbiditesi ve mortalitesi açısından önemine dikkat çekmek amaçlanmıştır.

\section{GEREÇ ve YÖNTEM}

Çalışmamızda Sağlık Bilimleri Üniversitesi Ankara Onkoloji Sağlik Uygulama ve Araştırma Merkezi'nde 2014-2018 yılları arasında elektif şartlarda yapılan 9,840 kolonoskopi işlemi retrospektif olarak taranmışır. Acil şartlarda yapılan kolonoskopiler çalışmaya dahil edilmemiştir. $\mathrm{Bu}$ çalışmada tanımlayıcı istatistik yöntemler kullanılmıştır.

\section{BULGULAR}

2014-2018 y1lları arasında elektif şartlarda yapılan 9,840 kolonoskopi işleminde, 7,024 hastada (\%71) total kolonoskopi işlemi yapılabilmiştir. 2,816 hastada $(\% 29)$ ise yetersiz temizlik, hasta intolerasyonu, geçişe izin vermeyen kitle gibi nedenlerle total kolonoskopi yapılamamıştır. Yapılan 9,840 kolonoskopi işlemi sonrasında toplamda 5 hastada $(0,05 \%)$ iatrojenik perforasyon olduğu görülmüştür. 3'ü kadın olan 4 hastada perforasyonun işlem esnasında farkedildiği ve hemen işlem sonrasında çekilen abdominal bilgisayarlı tomografide (BT) perforasyonun teyit edildiği görülmüştür. Yapılan tanısal laparoskopide sigmoid kolonda antimezenterik yüzde perforasyon alanının izlendiği ve laparoskopik olarak stapler yöntemi ile onarım yapıldığı görülmüşsür. Hastalar postoperatif dönemde sıkıntısız taburcu edilmiştir. Bir erkek hastanın ise işlem sonrası 16. saatte karın ağrıs1 nedeniyle acil servise başvurduğu ve çekilen abdomen BT sonrasında iatrojenik perforasyon ön tanısı ile yapılan laparotomide sigmoid kolonda antimezenterik yüzde perforasyon alanı görülmüştür. Batının kirli olmas1 nedeniyle Hartmann Prosedürü uygulanmıştır. Hasta postoperatif dönemde sıkıntısız taburcu edilmiştir.

\section{TARTIŞMA}

Kolonoskopi, kolorektal kanser taraması ve çeşitli kolorektal hastalıkların değerlendirilmesinde kullanilan standart yöntemdir. Komplikasyonlar, endoskopistin tecrübesi ile azalmakla birlikte, tüm diğer invaziv işlemler gibi kolonoskopide de olması kaçınılmazdır. Kolon perforasyonu, kolonoskopinin en ciddi komplikasyonlarından biridir.

Son zamanlarda yapılan çalışmalarda kolonoskopi sonrasında iatrojenik perforasyon oran $1 \% 0,016$ ile $\% 0,09$ arasında verilmektedir (6). Serimizde kolonoskopi sonrasinda iatrojenik perforasyon oranı literatür verileri ile benzer şekilde \%0,051 olarak tespit edilmiştir. Literatürde Brynitz ve arkadaşlarının 1986 yılında yaptığ çalışmada perforasyon oranı 1748 hastada \%0,629 olarak verilmiştir (7). 2001 yılında Sieg ve arkadaşlarının yaptığ çalışmada ise perforasyon oranı 82,416 hastada $\% 0,005$ olarak gösterilmiştir (8). İki çalışma arasındaki fark, geçen sürede endoskopistlerin deneyim kazanması ve gelişen teknoloji ile açıklanabilir. $\mathrm{Bu}$ durumu destekler şekilde, 2013 yılında Kim ve arkadaşlarının yaptığ 1 bir çalışmada, 12 yıllık bir sürede gerçekleştirilen 115,285 tanisal sigmoidoskopi/kolonoskopi işleminde 27 perforasyon $(\% 0,023)$ gerçekleştiği bildirilmiştir (3).

İatrojenik perforasyon sonrasında $\% 8,4$ 'lere kadar çıkabilen mortalite oranları bildirilmiştir (7-9). Çalışmamızda hastanemizde iatrojenik perforasyona bağlı 
mortalite olmadığ 1 görülmüştür. Perforasyon gelişen 5 hastanın 4'ünde hemen işlem sırasında, bir tanesinde ise ilk 24 saat içinde perforasyonun tespit edilmiş olması ve hızlıca müdahale edilmesinin bunun en önemli nedeni olduğunu düşünüyoruz. Erken tanı ve müdahalenin bu konuda en önemli belirteç olduğu söylenebilir.

Kolonoskopi sonrasında perforasyon açısından en önemli semptom karın ağrısıdır. Bir hastamız işlem sırasında saptanamayan perforasyon nedeniyle karın ağrısı şikayetiyle acil servise başvurmuştur. En yaygın perforasyon bölgesi sigmoid kolondur. Çalışmamızda 4 hastada sigmoid kolonda, 1 hastada ise inen kolonda perforasyon olduğu görülmüştür. Rektosigmoid veya sigmoid kolon-inen kolon bileşkesinde mobil sigmoid kolona bağlı keskin açılanma görülmekte ve bu durum germe kuvveti oluşturarak özellikle antimezenterik yüzde perforasyona yol açmaktadır. Çalışmamızda görülen 5 perforasyonun da benzer mekanizma ile antimezenterik yüzde olduğu görülmüştür. Geçirilen pelvik enfeksiyonlar ve adezyonlar kolonoskopi esnasinda perforasyon ihtimalini artırmaktadır (10). İşlem esnasında yapılan biyopsi ve polipektomi perforasyon riskini artırmaktadır. Çalışmamızda perforasyon saptanan 5 hastanın hiçbirinde perforasyon lokalizasyonundan biyopsi alınmadığı görülmüştür. Yaşl11ık, kadın cinsiyet, pelvik adezyon, kolonik tıkanma, terapötik kolonoskopi ve endoskopistin deneyimi perforasyon için risk faktörlerinden bazılarıdır (11).

Cerrahi yaklaşım; perforasyondan sonra geçen süreye, peritoneal kontaminasyon derecesine, hemodinamik stabiliteye, perforasyonun boyutuna, eş zamanlı kolorektal lezyonların varlığına ve cerrahın tecrübesine göre seçilir (12). Primer onarım en basit cerrahi yöntemdir, minimal periton kontaminasyonu, küçük perforasyon boyutu ve rezeksiyon gerektiren kolonik lezyon yokluğu durumunda yapilabilir. Primer onarım vakaların yaklaşık yarısında yapılabilirken erken dönemde kontrolü sağlamaktadır, morbiditeyi azaltmaktadır (13). Serimizde 4 hastada perforasyon işlem esnasında fark edilmiştir. Bu hastalarda laparoskopik primer onarım yapılmış ve ostomi açılmamıştır. Perforasyon sonrası kontaminasyona bağl1 enflamatuar değişiklikler ve peritonit nedeniyle ostomi açılması gerekebileceği unutulmamalıdır. İşlemden 16 saat sonra karın ağrıs1 ve peritonit bulguları ile acil servise başvuran hastaya Hartmann Prosedürü uygulanmak zorunda kalınmıştır. Peritoniti olmayan, belirgin kontaminasyonu olmayan, küçük perforasyonu olan seçilmiş hastalarda intravenöz sıv1, barsak istirahati ve intravenöz antibiyotiklerle konservatif tedavi yapılabilir (11).

Çalışmamızdaki 5 hastada olduğu gibi antimezenterik yüzde olan şafta bağlı perforasyonlar biyopsiye bağlı perforasyonlara göre daha büyük olmaktadır. Küçük boyutlu perforasyonlar veya müdahaleye bağl1 gecikmiş perforasyonlar işlem esnasında fark edilmeyebilir. Çalışmamızda 1 hastada perforasyon işlem esnasında tespit edilememiş ve işlem sonrası birinci gününde tespit edilerek hartmann prosedürü uygulanmak zorunda kalınmıştır. Perforasyonun erken tanısı hasta morbiditesi açısından çok önemlidir. Erken tanı alan küçük perforasyonlarda endoskopik klip uygulamas1 ile perforasyon alanı onarılabilmektedir. Çalışmamızdaki 4 hastada olduğu gibi laparoskopik olarak primer onarım da mümkün olmaktadır (14).

Sonuç olarak kolonoskopi sonras1 gelişen perforasyonlarda, perforasyonun erken dönemde tanınması ve müdahale edilmesi hasta morbiditesi açısından çok önemlidir. İatrojenik perforasyon sonrasinda tedavi yöntemi seçimi; hasta özellikleri, perforasyonun lokalizasyonu, boyutu ve perforasyon sonrası geçen süreye göre vaka bazlı yapılmalıdır.

\section{Çıkar çatışması: Yok}




\section{REFERANSLAR}

1. Winawer S, Fletcher R, Rex D, et al. Colorectal cancer screening and surveillance: clinical guidelines and rationale: update based on new evidence. Gastroenterology. 2003;124:544-602) Wexner SD, Garbus JE, Singh JJ. A prospective analysis of 13,580 colonoscopies. Reevaluation of credentialing guidelines. Surg Endosc. 2001;15:251-61.

2. Wexner SD, Garbus JE, Singh JJ. A prospective analysis of 13,580 colonoscopies. Reevaluation of credentialing guidelines. Surg Endosc. 2001;15:251-61.

3. Kim JS, Kim BW, Kim JI et al. Endoscopic clip closure versus surgery for the treatment of iatrogenic colon perforations developed during diagnostic colonoscopy: a review of 115,285 patients. Surg Endosc 2013;27: 501-4.

4. Samalavicius NE, Kazanavicius D, Lunevicius R et al. Incidence, risk, management, and outcomes of iatrogenic full-thickness large bowel injury associated with 56,882 colonoscopies in 14 Lithuanian hospitals. Surg Endosc 2013;27:162835.

5. Teoh AY, Poon CM, Lee JF et al. Outcomes and predictors of mortality and stoma formation in surgical management of colonoscopic perforations: a multicenter review. Arch Surg 2009;144:9-13.

6. Arora G, Mannalithara A, Singh G, Gerson LB, Triadafilopoulos G. Risk of perforation from a colonoscopy in adults: a large population-based study. Gastrointest Endosc. 2009; 69:3 :2
7. Brynitz S, Kjaergard H, Struckmann J. Perforations from colonoscopy during diagnosis and treatment of polyps. Ann Chir Gynaecol. 1986;75:142-5.

8. Sieg A, Hachmoeller-Eisenbach U, Eisenbach T. Prospective evaluation of complications in outpatient GI endoscopy: a survey among German gastroenterologists. Gastrointest Endosc. 2001;53:620-7.

9. Dulskas A, Smolskas E, Kildusiene I, Maskelis R, Stratilatovas E, Miliauskas P, Tikuisis R, Samalavicius N. Outcomes of surgical Management of iatrogenic colonic perforation by colonoscopy and risk factors for worse outcome. J BUON. 2019 Mar-Apr;24(2):431-435.

10. Park JY, Choi PW, Jung SM, Kim NH. The Outcomes of Management for Colonoscopic Perforation: A 12-Year Experience at a Single Institute. Ann Coloproctol. 2016;32(5):175-183

11. Panteris V, Haringsma J, Kuipers EJ. Colonoscopy perforation rate, mechanisms and outcome: from diagnostic to therapeutic colonoscopy. Endoscopy. 2009;41:941-51.

12. Mai CM, Wen $\mathrm{CC}$, Wen $\mathrm{SH}$, et al. Iatrogenic colonic perforation by colonoscopy: a fatal complication for patients with a high anesthetic risk. Int J Colorectal Dis. 2010; 25:449-54.

13. Teoh AY, Poon CM, Lee JF , et al. Outcomes and predictors of mortality and stoma formation in surgical management of colonoscopic perforations: a multicenter review. Arch Surg. 2009;144:9-13

14. Lüning $T H$, Keemers-Gels $M E$, Barendregt WB, Tan AC, Rosman C. Colonoscopic perforations: a review of 30,366 patients. Surg Endosc. 2007;21:994-7 